\title{
EDUCAÇÃO PELA VIA DA IMAGINAÇÃO: OS CONTOS DE FADAS COMO PILAR DO APRENDER IMAGINATIVO NA PERSPECTIVA DE G.K.
} CHESTERTON, J.R.R. TOLKIEN E C.S. LEWIS

\author{
EDUCATION THROUGH IMAGINATION: THE FAIRYTALES AS A BASIS FOR \\ THE IMAGINATIVE LEARNING FROM THE PERSPECTIVE OF G.K. \\ CHESTERTON, J.R.R. TOLKIEN, AND C.S. LEWIS
}

\section{Beatriz Teixeira Back ${ }^{1}$ \\ Gladir da Silva Cabral ${ }^{2}$}

\begin{abstract}
RESUMO: Mediante um estudo teórico, a presente pesquisa bibliográfica se propõe investigar de que maneira a imaginação, através dos contos de fadas, pode colaborar com o processo educativo, a fim de reafirmar a importância da literatura para a educação, bem como da imaginação para a aprendizagem. Com esse propósito, o artigo apresenta respectivamente: a relação entre educação e literatura, uma análise do conceito de imaginação em diferentes autores, o processo de formação do imaginário a partir da literatura, o processo de conhecimento segundo a perspectiva aristotélica e por fim, apresentará o pensamento de G.K. Chesterton, J.R.R. Tolkien e C.S. Lewis a respeito dos contos de fadas. Na conclusão evidencia-se o modo como os contos de fadas impactam na imaginação e, consequentemente, no processo educativo. Além disso, torna-se inteligível a urgência de uma (re)formação do imaginário e de uma educação que toma como princípio a imaginação, constituindo-se em aprender imaginativo.
\end{abstract}

PALAVRAS-CHAVE: Literatura. Aprendizagem. Poética. Imaginativo. Contos de Fadas.

ABSTRACT: This bibliographic research work presents a theoretical study on how imagination, through fairytales, can collaborate to the educative process, in order to reaffirm the importance of literature and imagination in education. Thus, this article presents: the relation between education and literature, an analysis of the concept of imagination in different authors, the process of formation of the imaginary based on literature, the process of knowledge according to the Aristotelian perspective and, finally, the thought of G.K. Chesterton, J.R.R Tolkien, and C.S. Lewis about fairytales. As a conclusion, the article shows how fairytales impact imagination and, as a consequence, the educative process. In addition, it shows the urgency of a reformation of the imaginary and of education taking imagination as a principle and favoring imaginative learning.

\footnotetext{
${ }^{1}$ Graduada em Pedagogia da Unesc. E-mail: bya.back@gmail.com

${ }^{2}$ Doutor em Estudo Linguísticos e Literários. Professor da Unesc. E-mail: gla@ unesc.net

Saberes Pedagógicos, Criciúma, v. 4, n² , maio/agosto 2020.-Curso de Pedagogia- UNESC
} 


\section{SABERES PEDAGÓGICOS}

Revista do Curso de Graduaçūo de Pedagogia - Unesc

ISSN 2526-4559

KEYWORDS: Literature. Learning. Poetics. Imagination. Fairytales.

\section{INTRODUÇÃO}

No princípio da obra Metafísica, Aristóteles afirma que "todo homem, por natureza, deseja saber" (2012, p. 41). Mas como o homem, animal racional, é capaz de saber? Como aprende? E o que é aprender? Essas são interrogações que permearam a história da Pedagogia, bem como o de outras ciências como a filosofia, a epistemologia e a psicologia.

Mesmo diante das diferentes correntes pedagógicas, é possível perceber que, com o curso da modernidade, houve uma absolutização da razão e uma tendência a reduzir o mundo à técnica e à ciência, que o vê como algo certo e mecânico. Dentro da perspectiva segundo a qual aprender é submeter a realidade aos parâmetros científicos, a imaginação é abandonada e desprezada, o que vai na contramão daquilo que os antigos compreendiam como educação - como inseparável da imaginação. O que parecia algo bastante claro tornouse nublado, mas alguns escritores se levantaram para resgatar a necessidade da imaginação para o homem, elucidando a união entre literatura e educação; entre eles estão George MacDonald (1824-1905), G.K. Chesterton (1874-1936), J.R.R. Tolkien (1892-1973), C.S. Lewis (1898-1963) e Northrop Frye (1912-1991).

De maneira especial, G.K. Chesterton defendia a filosofia dos contos de fadas em contraposição ao determinismo racional científico, o que fica explícito quando diz: "Encontrei o mundo moderno às voltas com o fatalismo científico, afirmando que as coisas são como sempre deviam ter sido, sucedendo-se, invariavelmente, desde que o mundo é mundo" (CHESTERTON, 2013 a, p. 93). Ele encontrou nas histórias de fadas o seu oposto, isto é, um mundo de possibilidades capaz de avivar a imaginação humana e potencializar sua razão, e desse modo, revelar a realidade do mundo; não como algo mecânico, mas algo contingente.

A partir desses autores do século XIX e XX, pretende-se com esta pesquisa investigar a relação entre literatura e educação, imaginação e aprendizagem. De maneira especial, este estudo investigará a importância dos contos de fadas para a aprendizagem, para o conhecimento da realidade e de si mesmo, norteado pelo problema: "De que maneira a imaginação, através dos contos de fadas, pode colaborar com o processo de conhecimento?”.

Saberes Pedagógicos, Criciúma, v. 4, n², maio/agosto 2020.- Curso de Pedagogia- UNESC 


\section{SABERES PEDAGÓGICOS}

Revista do Curso de Graduaçūo de Pedagogia - Unesc

ISSN $2526-4559$

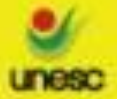

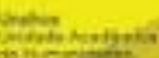

Em vista disso, é fundamental alcançar os objetivos específicos de: 1) esclarecer a relação entre educação e literatura; 2) sintetizar o conceito de imaginação a partir de diferentes autores; 3) descrever as funções da imaginação e do imaginário; 4) compreender o processo de formação do conhecimento 5) investigar o pensamento de G.K. Chesterton, J.R.R. Tolkien e C.S. Lewis referente aos contos de fadas e a sua relação com o processo educativo.

O presente trabalho, que se trata de uma pesquisa bibliográfica, seguirá uma abordagem qualitativa, que é "como uma trajetória circular em torno do que se deseja compreender, não se preocupando unicamente com princípios, leis e generalizações, mas voltando o olhar à qualidade, aos elementos que sejam significativos para o observadorinvestigador" (SANTOS; SANTOS, 2010, p. 42). De maneira descritiva e explicativa, o artigo se propõe a esclarecer os conceitos de educação e literatura, de modo a estabelecer suas relações e os pontos em que compactuam. Em seguida, serão discutidos os conceitos de imaginação e imaginário em diferentes autores, esclarecendo o processo de formação do imaginário. Na terceira parte, será descrito o processo de conhecimento do ser humano segundo a perspectiva aristotélica, que abarca o processo cognitivo e o método de conhecimento. Na quarta parte far-se-á um estudo teórico sobre os contos de fadas, levantando um breve histórico sobre esses contos ao longo do tempo e discutindo a visão de G.K. Chesterton, J.R.R. Tolkien e C.S. Lewis a respeito dos contos de fadas e seus efeitos. Por fim, a conclusão, trará uma síntese do pensamento desses autores, a fim de responder à maneira pela qual a imaginação, através dos contos de fadas, pode colaborar com o processo de conhecimento.

Os contos de fadas, escritos a partir dos séculos XVI e XVII, são narrativas que foram grandes conselheiras para os seres humanos durante a história, no entanto surgiram aqueles que não souberam apreciar tais histórias com os olhos de criança, como nos recorda Chesterton (2013 a), e por essa razão as desprezaram. Negaram a capacidade desses contos de despertar tanto a imaginação quanto a razão, chamando-os de modo desprezível de "contos de carochinha". C.S. Lewis também denuncia aqueles que rejeitam os contos de fadas por supostamente afastar as crianças da realidade ou passar a elas uma falsa impressão do mundo real. Segundo Lewis, são justamente os contos de fadas que permitem às crianças um encontro mais pleno e verdadeiro com o mundo (LEWIS, 2009).

Saberes Pedagógicos, Criciúma, v. 4, n², maio/agosto 2020.- Curso de Pedagogia- UNESC 
Embora ainda se prezem os contos de fadas no âmbito da educação infantil, há pouco destaque em relação a seus benefícios sobre a imaginação e, consequentemente, para a aprendizagem e a educação. Os resultados disso já foram anunciados pelos literatos com olhos de crianças, como destaca Márcia Xavier Brito no prefácio à edição brasileira do Fabuloso Livro Azul de Andrew Lang (2016, p. 30), ao relatar sobre a importância dos contos de fadas:

Educar sem oferecer a possibilidade da formação de juízos de valor baseados nessa constante comum da humanidade, sem reconhecer os limites da realidade, no dizer de Chesterton, "o material que pode ser facilmente quebrado", é criar, como dizia C.S. Lewis, "primatas de calças" - indivíduos verdadeiramente destituídos da capacidade humana de imaginar ou de sentir, que se tornarão "homens sem peito", os homens desumanos, depressivos e entediados da sociedade moderna.

Por essa razão, e por não haver uma grande quantidade de trabalhos acadêmicos seguindo esta abordagem, a pesquisa se propõe a resgatar aquilo que parece ter sido esquecido pelos pensadores modernos: a literatura como base da educação, a imaginação como o princípio da aprendizagem e os contos de fadas como uma pujante forma literária de enriquecer o imaginário e, consequentemente, de formar o ser humano em diferentes dimensões.

Os objetivos da pesquisa foram traçados a fim de elaborar uma resposta para o problema selecionado e de modo a levantar as necessidades de trazer a imaginação para o centro das preocupações da educação, a fim de alcançar o reconhecimento da urgência de uma reforma do imaginário e de uma educação da imaginação e pela imaginação, temas centrais e transversais ao que o artigo se propõe, não obstante demasiadamente urgentes para a qualidade da educação atual.

\section{EDUCAÇÃO E LITERATURA}

Para desvendar a relação entre educação e literatura, é salutar trazer o significado de ambos os conceitos e áreas, a fim de compreender e analisar seus pontos de intersecção, em que se tornam indissociáveis.

Educar, em seu significado etimológico, remonta ao sentido de "tirar de dentro" ou "conduzir para fora" (ex + ducere $)$, evidenciando a essência da educação, que é uma Saberes Pedagógicos, Criciúma, v. 4, n² 2, maio/agosto 2020.- Curso de Pedagogia- UNESC 
atividade que leva em consideração tanto o esforço pessoal de procurar tirar de si as suas potencialidades, quanto a ajuda prestada pelos outros para que se chegue a esse fim. Dom Lourenço de Almeida Prado afirma que:

Educação é o processo vital, radicado na natureza espiritual e perfectível da criatura humana, pelo qual essa criatura, com o apoio do convívio social, particularmente com o da família e dos que a antecederam, vai desdobrando as suas energias germinais interiores, que traz ao nascer, e conduzindo-as à plenitude atuante e, ao mesmo tempo, toma posse do patrimônio da cultura e civilização acumulado pelas gerações precedentes, e se insere, como membro vivo e participante, na comunidade humana de seu tempo e nos hábitos e peculiaridades do seu povo e sua região. (1991, p. 76)

O mesmo autor expõe que o fim da educação é a conquista da liberdade interior, tomada enquanto a capacidade de compreender, avaliar e escolher, não com base nos próprios desejos, mas de modo consciente, racional e moral. Esse princípio da educação identifica-se com o que é chamado de "Educação Clássica", que remete à tradição pedagógica da Grécia Antiga e da civilização cristã. Segundo o livro Paidéia: a formação do homem grego:

Uma educação consciente pode até mudar a natureza física do Homem e suas qualidades, elevando-lhe a capacidade a um nível superior. Mas o espírito humano conduz progressivamente à descoberta de si próprio e cria, pelo conhecimento do mundo exterior e interior, formas melhores de existência humana. A natureza do Homem, na sua dupla estrutura corpórea e espiritual, cria condições especiais para a manutenção e transmissão da sua forma particular e exige organizações físicas e espirituais, ao conjunto das quais damos o nome de educação. Na educação, como o Homem a pratica, atua a mesma força vital, criadora e plástica, que espontaneamente impele todas as espécies vivas à conservação e propagação de seu tipo. É nela, porém, que essa força atinge o mais alto grau de intensidade, através do esforço consciente do conhecimento e da vontade, dirigido para a consecução de um fim. (JAEGER, 2003, p. 3-4)

Em consequência, a educação não pode ser instrumentalização da pessoa e não se concretiza sem a clarificação da inteligência que se torna capaz de conhecer. Por essa razão é que a educação é, sobretudo, um processo de dentro para fora, pois de modo contrário, aproxima-se de uma domesticação em que o educador impõe ao aluno o que fazer.

Em uma autêntica educação humana, como a defendida na Grécia Antiga, o indivíduo a ser educado é levado à liberdade, análoga à liberdade dos gregos, que mesmo prisioneiros eram livres por meio da educação. Esse aspecto sempre foi privilegiado pela Saberes Pedagógicos, Criciúma, v. 4, n², maio/agosto 2020.- Curso de Pedagogia- UNESC 
Educação Liberal, “cujo termo foi cunhado na Idade Média e se referia, originalmente, às artes liberais ou profissões livres, como diríamos hoje, em oposição às profissões servis, em que o trabalhador exercia uma função em troca de um salário" (ZAMBONI, 2011, p. 135). Destituída de qualquer relação com o liberalismo econômico, essa educação oriunda da tradição clássica, significa "ordenação e integração do conhecimento para o benefício do indivíduo livre - em contraste com a educação técnica ou profissionalizante" (KIRK, 200apud ZAMBONI, 2011, p. 136).

A educação liberal clássica tem como finalidade a excelência humana, visa a formação do homem livre por meio do domínio das artes liberais - Gramática, Retórica e Lógica -, de modo que o ser humano possa compreender problemas básicos e estabelecer suas relações. Essa tradição das artes liberais pretende introduzir o homem nas questões primordiais da humanidade de modo a compreender ideias que são importantes para os problemas mais básicos da vida humana, e denota como objetivo primordial e fim último da educação a formação do homem por inteiro; sendo que o homem constitui o próprio fim da educação, e não um meio para algum fim. Nesse mesmo sentido, o filósofo da educação Jacques Maritain (1882-1973), defensor da educação liberal, coloca que a finalidade educativa é:

[...] guiar o homem no desenvolvimento dinâmico do curso do qual se constituirá como pessoa humana, - dotada das armas do conhecimento, do poder de julgar e das virtudes morais - transmitindo-lhe ao mesmo tempo o patrimônio espiritual da nação e da civilização às quais pertence e conservando a herança secular das gerações. (MARITAIN, 1968, p. 36)

Grande parte do patrimônio histórico, cultural e moral da humanidade se encontra na literatura e nos mitos das civilizações, nas sociedades de cada época. Destarte, o acesso à literatura permite a compreensão dessa herança secular de símbolos, analogias e significadoschave, essenciais para o desenvolvimento da inteligência, da consciência de si e da percepção do outro no mundo.

Como coloca o escritor canadense Northrop Frye, em sua obra Imaginação educada (2017, p. 23): “[...] a literatura pertence ao mundo que o homem constrói, e não ao mundo que ele vê; pertence ao seu lar, e não ao seu ambiente. O mundo literário é um mundo 
humano concreto de experiência imediata". Por esse motivo, o acesso à criação literária permite uma profunda formação humana, uma vez que torna acessível a experiência humana, aquilo que não é transmissível como outros conhecimentos, e por isso "permite compreender as vivências alheias por meio de símbolos que evocam experiências análogas" (ZAMBONI, 2016, p. 221). Isto é, a literatura permite-nos vivenciar o mundo a partir do olhar e da experiência do outro.

Por enquadrar-se no discurso poético, a literatura propicia o conhecimento de experiências possíveis e, portanto, transcende a própria história, por abarcar tanto o que aconteceu como aquilo que poderia ter acontecido. Julián Marías, a respeito dos efeitos da literatura, argumenta que ela:

Introduz o desdobramento da imaginação, a exploração de irrealidades que têm existência puramente mental [...] a experimentação imaginativa das possibilidades humanas [...] a invenção de situações não realizadas e mesmo irrealizáveis, o descobrimento e a experiência de inumeráveis sentimentos, relações humanas, projetos de vida; das forças e poderes que condicionam a vida, desde o seu desenlace, a antecipação da própria morte (ou a de outros) e a compreensão de seu sentido. [...] desta nova situação depende a possibilidade do pensamento complexo, os mecanismos de indagação, descobrimento, concatenação, justificação, prova; em suma, a construção de edifícios mentais em que se realizam a filosofia, a teologia, as ciências da natureza ou as humanidades, a indagação da realidade inteira e do que se descobre como possível, desejável ou temível. A literatura é o mais formidável instrumento de dilatação da vida humana. (MARÍAS, 1995 apud ZAMBONI, 2016, p. 207)

Logo, a experiência humana é construída e enriquecida pela literatura, que permite vivências imaginativas irreais, possíveis ou até mesmo irrealizáveis, mas nem por isso pouco vívidas e não vividas. Essas experiências imaginativas são capazes de preparar o indivíduo para a vida real, uma vez que, para que algo seja feito, deve ter sido imaginado antes, como se fosse pré-vivido e pré-experienciado na mente. E como nossa experiência pessoal é muito limitada, a literatura é uma rica oportunidade para agregarmos nossa experiência e formarmos nosso "universo interior", a partir da experiência de outrem que se concretiza em nós como experiência imaginativa. Por isso, Fausto Zamboni afirma que "a literatura propicia o conhecimento de muitas vidas possíveis e de variadas dimensões da intimidade humana; dános, numa palavra, uma verdadeira 'geografia das emoções'” (2016, p. 207). A partir disso, 
pode-se concluir que, aquele que tem uma escassa experiência imaginativa, fica limitado à sua reduzida experiência pessoal, o que o limita em diferentes aspectos.

\section{O EXERCÍCIO DA IMAGINAÇÃO E A FORMAÇÃO DO IMAGINÁRIO}

A literatura propicia o desenvolvimento da imaginação e do imaginário, como deixa claro George MacDonald quando afirma que "na cultura da imaginação, os livros, embora não sejam os únicos, são os meios mais fáceis de fornecer o alimento conveniente para ela" (1867, p. 19). Desse modo, como é capaz de propiciar uma enriquecedora formação do imaginário, é peça-chave para o desenvolvimento intelectual, cultural e moral, abarcando o ser humano em sua integralidade. Para MacDonald, educação é movimento, renovação, despertamento, "constante questionamento do passado visando a interpretação do futuro" (2013, p. 1), portanto, é algo dinâmico e criativo.

A imaginação, defendida aqui como princípio da educação, pode ser definida de diferentes formas. De maneira geral, segundo Régis Jolivet (1955, p. 148), “chama-se imaginação a faculdade de conservar, de reproduzir e de combinar as imagens das coisas sensíveis". Quando Aristóteles discorre sobre o discurso poético, retrata a imaginação como a função da mente que, unida à memória em uma mesma faculdade, é responsável por combinar e fundir as imagens captadas pelos sentidos externos no encontro com a realidade, esquematizando-as para a construção de um conceito e de relações possíveis. A imaginação é, portanto, a mediadora entre a faculdade dos sentidos e a faculdade do pensamento (ARISTÓTELES, 2005).

O discurso poético, que versa sobre o possível, na perspectiva aristotélica, dirigese à imaginação, ao mesmo tempo que a requer para ser "compreendida" e apreciada, uma vez que a função do poeta, bem como sua obra: "não consiste em contar o que aconteceu, mas sim coisas quais podiam acontecer, possíveis do ponto de vista da verossimilhança ou da necessidade” (ARISTÓTELES, 2005, p. 28). Logo, cabe ao ouvinte do discurso poético permitir que a imaginação tome as rédeas da mente para conceber o possível.

Para São Tomás de Aquino (1225-1274), filósofo medieval que abraçou as ideias de Aristóteles, o homem possui quatro sentidos internos: o sentido comum, a imaginação, a Saberes Pedagógicos, Criciúma, v. 4, n², maio/agosto 2020.- Curso de Pedagogia- UNESC 
estimativa e a memorativa (AQUINO, 2003, S. STh. I, q. 78, a. 4, c.). Ele define a imaginação como um "tesouro das formas recebidas pelos sentidos", ou seja, o ato de imaginar consiste em apreender, reproduzir e associar imagens que provêm dos sentidos externos, sendo esse ato uma potência sensitiva interna. Capaz de combinar e relacionar imagens, a imaginação faz vigorar a criatividade, responsável por reproduzir em uma nova forma o que a imaginação captou pelos sentidos, algo essencial à literatura fantástica (FAITANIN, 2008).

A faculdade imaginativa apresenta as funções reprodutora e criadora. A primeira consiste em reproduzir ou evocar as imagens captadas pelos sentidos, todavia diferenciandose da memória, a qual tem por objeto os estados de consciência antigos, em vez das imagens sensíveis em si mesmas. Por sua vez, a função criadora ou construtora é responsável por combinar as imagens recebidas pelos sentidos de modo a formar novas imagens, o que pode ocorrer de forma espontânea através dos sonhos e de forma ativa e refletida em que o espírito conscientemente cria conjuntos de imagens novas, produzindo a fantasia (JOLIVET, 1955).

Responsável por evocar as imagens sensíveis e as combinar de diferentes modos, a imaginação é uma faculdade da mente útil e necessária capaz de produzir ciência e belas artes. Todavia, diante dessas funções, ela difere-se daquilo que se chama de imaginário ou repertório imaginativo, que se refere ao "lugar" em que essas imagens captadas pelos sentidos ficam depositadas. É desse depósito de imagens que a mente extrairá o conteúdo para realizar as funções imaginativas, tornando-se o imaginário um repertório de possibilidades de criação, em que ficarão depositados os produtos da imaginação criadora.

Northrop Frye conceitua imaginação como "o poder de construir modelos possíveis de experiência humana" (FRYE, 2017, p. 18). Nesse nível em que atua a mente humana, nada acontece de forma real e factual, porém tudo pode acontecer, pois nesse universo trabalha-se com possibilidades e com a experiência imediata. Por essa razão, o autor afirma que o conteúdo da literatura não é real nem irreal. Uma vez que não é função do poeta fazer afirmações factuais ou particulares, a obra poética não informa o que aconteceu, mas o que acontece e aquilo que se dá sempre. É o que Aristóteles chamou de evento humano típico ou universal. Em razão disso é que a linguagem poética trabalha com símbolos, pois há sempre presente elementos da vida humana que encontrarão neles alguma correspondência, semelhança ou representação, aproximando o natural e o humano (FRYE, 2017). Essa Saberes Pedagógicos, Criciúma, v. 4, n², maio/agosto 2020.- Curso de Pedagogia- UNESC 
correspondência presente na literatura chama-se alegoria, a qual pode ser tanto direta quanto indireta.

Alguns escritores de fantasia, os quais utilizaram da linguagem poética para possibilitar aos leitores de suas obras fantásticas a vivência de experiências, discorreram sobre a imaginação, como George MacDonald, pastor escocês do século XIX e escritor. Ele coloca que a imaginação é a faculdade responsável por dar forma ao pensamento, no entanto deixa claro que tais formas não nascem da mente humana. O que há é a percepção de uma forma já existente na realidade, que se torna visível pela imaginação. Para ele, a imaginação é também a base da experiência literária. "Metade da nossa linguagem é obra da imaginação" (MACDONALD, 2013, p. 5). A imaginação é a essência da linguagem poética, que se distingue da linguagem comum, cotidiana.

Ao colocar a imaginação como faculdade criadora do homem, MacDonald deixa claro que ela não é em nenhum sentido primário criativa, já que não pode escolher senão as formas já existentes na realidade. Não obstante, sua operação procede de modo divino, pois de certo modo põe o pensamento em forma. MacDonald (2013). não vê a imaginação e a ciência como dimensões distintas e totalmente separadas, pelo contrário. Nesse mesmo sentido discorrerá J.R.R. Tolkien, o filólogo, professor universitário e escritor de fantasia que ficou amplamente conhecido pela produção das obras literárias $O$ Senhor dos Anéis. Ele apresenta, em seu ensaio "Sobre histórias de fadas", essa faculdade criadora do homem como uma capacidade subcriadora, capaz de criar um mundo secundário permeado de regras e leis próprias.

A linguagem literária das histórias fantásticas, capazes de levar a imaginação a elevado desenvolvimento, enriquece a experiência humana, como expressa Frye: "Não importa quanta experiência acumulemos ao longo dos anos, jamais alcançaremos em vida toda a dimensão da experiência proporcionada pela imaginação" (2017, p. 89). Portanto, a literatura é importante para o processo educativo, uma vez que permite o desenvolvimento da imaginação, princípio da aprendizagem como veremos adiante. Mas de que modo a imaginação interfere na aprendizagem, sendo necessária ao processo educativo? 


\section{SABERES PEDAGÓGICOS}

Revista do Curso de Graduaçāo de Pedagogia - Unesc

ISSN $2526-4559$

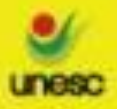

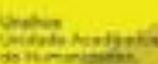

\section{O PROCESSO DE CONHECIMENTO E O APRENDER IMAGINATIVO}

É necessário voltar novamente à pergunta: “Como o homem aprende?”. Para Aristóteles, o conhecimento humano origina-se nas sensações, naquilo que os cinco sentidos nos apresentam. Mas existe uma função no ser humano fundamental para o processo de conhecimento, que não existe da mesma maneira em nenhum outro animal: a memória - a qual identifica-se com a faculdade imaginativa e é, portanto, intitulada de fantasia.

De maneira geral, o ser humano é capaz de conhecer através de um processo natural e progressivo, que se dá da seguinte maneira: primeiramente, ocorre a percepção, em que a pessoa recebe a informação sensorial. Dessa informação, guarda-se um esquema ou fantasma, isto é, uma imagem esquemática de algo que foi percebido e que é guardado na memória. Dessas imagens, o intelecto abstrai a essência das coisas e produz o conceito (JOSEPH, 2008).

O processo vai da percepção das imagens, que são realidades concretas e singulares, à elaboração do conceito ou ideia, que são abstratos e gerais. Esse processo pode ser chamado de abstração, definido como: "Enquanto operação que produz a ideia geral, a abstração é o ato pelo qual a inteligência pensa um objeto, deixando de lado seus caracteres singulares" (JOLIVET, 1955, p. 195). Logo, o conhecimento da essência das coisas torna-se possível, o que só acontece pelo uso da faculdade da imaginação.

Segundo Aristóteles “a imaginação, por seu turno, é algo diferente da percepção e do pensamento discursivo. Ela não sucede, de facto, sem a percepção sensorial, e sem ela não existe suposição" (2010, p. 110). O papel da imaginação é assim evidente: unir a faculdade dos sentidos à do pensamento, isto é, "a faculdade perceptiva e a faculdade científica da alma [...] a última, o cientificamente cognoscível; a primeira, o sensível." (ARISTÓTELES, 2010, p. 123). Ligando o particular que é concebido pelos sentidos ao universal concebido pelo intelecto, já não é mais necessário, por exemplo, perceber todas as cadeiras existentes no mundo para conhecer uma cadeira, basta conhecer sua essência para saber o que é uma cadeira (JOSEPH, 2008).

Por essa razão, a imaginação assume um papel de mediação entre o conhecimento sensível e o conhecimento lógico do pensamento, isto é, ela é responsável por estabelecer uma Saberes Pedagógicos, Criciúma, v. 4, n², maio/agosto 2020.- Curso de Pedagogia- UNESC 
ponte entre os abismos dos dados dos sentidos e do raciocínio; entre o mundo exterior e o mundo interior. Uma vez que é essencialmente elemento mediador, a imaginação é indispensável para o processo de conhecimento, responsável por interligar a razão e a experiência, funções complementares que contribuem juntas para esse processo. Isso constitui, na linguagem aristotélica, a passagem do conhecimento animal para o conhecimento racional - ou da potência para o ato -, naquele que é animal racional.

Logo, a partir dessa perspectiva aristotélica, a inteligência humana opera sobre os fantasmas, de modo que todo o conhecimento depende do que está na memória do indivíduo, ou em uma linguagem mais contemporânea, depende do que está no imaginário - repertório imaginativo. Por essa razão, há a grande urgência de se ter um imaginário rico e bem formado, porque dele depende todo conhecimento. Da mesma maneira, o constante exercício da imaginação é fundamental porque, como foi explanado acima, o trabalho da inteligência é um trabalho de imaginação, o que evidencia que todo aprender é um processo imaginativo.

Esse processo de conhecimento é uma unidade orgânica que opera de modo contínuo, partindo das sensações, passando pela imaginação e culminando no pensamento racional. Sendo assim, melhores serão os raciocínios quanto mais conteúdo houver no repertório imaginativo, quanto mais desenvolvida for a imaginação. Encontra-se aí a razão de a imaginação ser defendida como o princípio da educação.

\section{CONTOS DE FADAS}

As histórias, enquanto narrativas mitológicas e fantásticas, sempre existiram na humanidade e foram para os homens as primeiras conselheiras. Os mitos explicavam, para os antigos, mistérios e fenômenos naturais, incluindo a origem do mundo e o surgimento do dia e da noite. Além dos mitos, entre as histórias antigas estão as lendas e o folclore, que são narrativas ligadas mais à cultura e ao conhecimento de povos particulares. Essas histórias, no entanto, se diferenciam daquelas que os estudiosos classificam e denominam como contos de fadas, já que falam sobre a realeza, heróis, gigantes, fadas, anões magos, bruxos, entre outros seres fantásticos e não-fantásticos, e também não possuem autores conhecidos, uma vez que 
são oriundos de tradição oral e muitos elementos das narrativas acabaram se modificando com o tempo.

Segundo Nelly Novaes Coelho, os contos de fadas se caracterizam como histórias com um eixo gerador de uma problemática existencial, relacionada à realização do herói ou da heroína. A autora coloca:

A efabulação do conto de fadas expressa os obstáculos ou provas que precisam ser vencidas, como um verdadeiro ritual iniciático, para que o herói alcance sua autorealização existencial, seja pelo encontro de seu verdadeiro eu, seja pelo encontro da princesa, que encarna o ideal a ser alcançado. (COELHO, 1987, p. 13)

Não é possível constatar quando exatamente surgiram os contos de fadas, eles estiveram presentes em diferentes culturas (celta, chinesa, oriental, árabe, judaica, entre outras). Passaram pela Idade Média com histórias sobre cavaleiros, fadas e damas amadas; pelo Renascimento do século XVI, com textos de origem popular recriados por uma elaboração erudita, em que permanecem as obras de atmosfera mágica céltico-bretã. Ao final do século XVII, houve um declínio dessas narrativas fantásticas na França, que são transformadas em narrativas populares folclóricas ou em romances sentimentais. Todavia, a partir de Perrault, os contos de fadas ressurgem com a publicação de contos e a criação do núcleo de literatura infantil ocidental. Nessa mesma época, os contos eram criados destinados ao prazer e divertimento da corte de Luís XVI (COELHO, 1987).

Os contos de fadas resistem até o final do século XVIII. No entanto, com a eclosão da Revolução Francesa em 1789, em que o uso da razão prevalece, os contos escapam ao interesse dos adultos e passam a fazer parte do mundo infantil. Com o início do século XIX, entram em cena os irmãos Grimm e Hans Christian Andersen, resgatando o espírito dos contos de fadas. Além desses, outros grandes compiladores fizeram parte da história, como Jean De La Fontaine (séc. XVII) e Andrew Lang (séc. XIX e XX).

Apesar do fim dos salões da monarquia francesa com a Revolução Francesa, em que os contos de fadas eram contados para a diversão da corte, a tradição das histórias de fadas não acabou, mas ultrapassou os séculos, trazendo suas maravilhas e um grandioso aparato imaginativo. Mesmo diante da modernidade, que se opõe à imaginação em defesa de um empirismo vazio, os contos permanecem com sua imortal importância para a humanidade,

Saberes Pedagógicos, Criciúma, v. 4, n², maio/agosto 2020.- Curso de Pedagogia- UNESC 


\section{SABERES PEDAGÓGICOS}

Revista do Curso de Graduaçāo de Pedagogia - Unesc

ISSN 2526-4559

e autores como G.K. Chesterton, J.R.R. Tolkien e C.S. Lewis, defenderam de maneira perseverante, os quais serão abordados a seguir.

\subsection{G.K. Chesterton e o país das fadas}

Gilbert Keith Chesterton (1874-1936), mais conhecido como G.K. Chesterton, foi um escritor, poeta, filósofo, jornalista e crítico literário que revelou ter sua vida formada pelos contos de fadas quando expressou: "a minha primeira e última filosofia, aquela na qual acredito com uma certeza inquebrantável, foi a que aprendi na escola maternal" (2013, p. 79). Essa filosofia é o que se chama de contos de fadas. Em sua obra Ortodoxia, é possível compreender sua visão sobre esses contos, ao falar a respeito da "terra dos elfos" e, também, no seu livro Contos de fadas e outros ensaios literários.

Em um artigo de jornal publicado em 1905, Chesterton afirma que "os contos de fadas são coisas extraordinárias vistas por pessoas ordinárias”. Diferentemente da moderna fantasia, que narra coisas ordinárias vistas por pessoas extraordinárias, "os contos de fadas são um quadro da vida permanente da grande massa da espécie humana muito mais realista que a mais realista ficção" (CHESTERTON, 1905, s/p). Isto é, trata-se daquela vida comum que a maioria dos homens experimenta durante o maior número de séculos, a vida do campo e das relações simples.

Chesterton afirma que os contos de fadas são absolutamente racionais, uma vez que admitem a lógica e a necessidade das coisas, respeitando as ciências das relações mentais; como, por exemplo, se John é o filho carpinteiro, o carpinteiro é pai de John, diferentemente de como procedem os homens da ciência, que colocam a necessidade e as leis em eventos ou fenômenos físicos, em que há apenas estranhas repetições. Dessa maneira, enquanto os cientistas afirmam algo quando na realidade estão apenas apostando, através de uma série de observações, a sábia filosofia do país das fadas expressa a arbitrariedade dos fatos e se abre ao mistério ou ao misticismo.

O misticismo presente nos contos de fadas leva ao realismo, de modo que através do mundo das fadas é possível enxergar melhor o mundo dos homens. Por meio desses contos, o leitor tem acesso a coisas misteriosas sobre as quais não se sabe a origem e nem o Saberes Pedagógicos, Criciúma, v. 4, n², maio/agosto 2020.- Curso de Pedagogia- UNESC 
porquê. Por exemplo, uma caixa é aberta e todos os males saem voando, como no mito da caixa de Pandora. Esses acontecimentos misteriosos causam surpresa e maravilhamento, uma vez que é percebendo como as coisas não são que as percebemos como são, como observa Chesterton quando diz: "esses contos nos dizem que as maçãs são douradas unicamente para relembrarem o esquecido momento em que verificamos serem elas verdes" (CHESTERTON, 2013 a, p. 86). Assim, o leitor se depara com a realidade à sua volta, a qual se tornara trivial e familiar a ponto de não mais maravilhar-se com ela como as crianças se maravilham, como sendo algo novo e contingente; além de perceberem que as coisas são como são não por uma necessidade inalterável, mas como que por "mágica", como nos contos de fadas.

A consciência da contingência do mundo real é fruto da imaginação que é despertada pelos os contos de fadas, o que se contrapõe à visão de cientistas que olham a realidade como sendo mecânica, fruto de uma dormência da imaginação que não é capaz de perceber que as coisas poderiam ser de outra maneira. Por essa razão, Chesterton diz que "o homem que fala sobre uma lei que nunca viu é que é o místico. Mais ainda: o homem comum da ciência é, estritamente, um sentimental” (2013 a, p. 84). Ele exige e espera o efeito que uma determinada causa recorrente traz, dando o nome de lei a uma série de observações sobre alguns efeitos. Mas de modo oposto se comporta o homem do país das fadas, ele é racional, uma vez que é capaz de imaginar o mundo de outra maneira e maravilhar-se com a realidade em suas estranhas repetições (CHESTERTON, 2013 a).

Outra característica dos contos de fadas é o que Chesterton chama de "Doutrina da alegria condicional”, a qual revela que, segundo a moral do país da fadas, a virtude repousa em um $s e$, isto é, toda a felicidade se apoia em alguma condição incompreensível, a qual precisa ser cumprida para desfrutar-se da felicidade. Essa é a questão ética do país das fadas, sobre a qual o autor diz:

Dê uma pancada forte em um vidro e ele não durará um instante; não lhe toque e ele durará mil anos. Tal era, segundo me parecia, a alegria humana, quer no País das Fadas, quer na própria Terra. A felicidade só dependia de não fazer alguma coisa que em qualquer momento poderia ser feita e, muitas vezes, sem que fosse óbvia a razão pela qual não se devia fazê-la. (CHESTERTON, 2013 b, p. 90) 
Desse modo, há um paralelo e uma semelhança entre a ética dos elfos e a dos homens, que também se apresenta com a restrição de algumas coisas para que se possa desfrutar de todo o resto. Essa moralidade dos contos de fadas revela que eles não estão longe de leis, mas pelo contrário, vão à raiz de toda lei (CHESTERTON, 2013 b).

A visão de G.K. Chesterton sobre os contos de fadas, a qual é retratada de modo filosófico, revela que uma dormência da faculdade imaginativa produz uma falsa ciência, que acredita ter desvendado os mistérios do mundo por uma série de observações e recorrências, enquanto que fechando-se ao verdadeiro mistério - à possibilidade de ocorrer o inesperado gera um determinismo sentimental. Isso revela que o conhecimento sem a imaginação não é verdadeiro conhecimento, pois, ou fica preso aos dados dos sentidos, ou fica preso ao conhecimento do intelecto. Em outras palavras, o conhecimento científico sem imaginação corre o risco de permanecer no conhecimento da realidade sensível, limitando-se aos efeitos e fenômenos visíveis, aparentemente mecânicos do mundo. Ou corre o risco de limitar-se no campo do formalismo conceitual, sem ligação com a realidade da experiência. Somente quando a imaginação mediadora atua no processo de elaboração do conhecimento é que se chega à essência das coisas.

Os contos de fadas, amplamente defendidos por Chesterton, não ferem a lógica, como já evidenciado pelo escritor. Uma vez que se encaixam no discurso poético, envolvem o que é possível, mesmo que possa ser inverossímil. Dirigindo-se à imaginação, esses contos que fazem parte do "ensolarado país do bom senso" apresentam-se como parte integrante do processo educativo, na medida em que operam no nível poético, o qual está na base do conhecimento.

\subsection{J.R.R. Tolkien e os efeitos dos contos de fadas}

John Ronald Reuel Tolkien (1892-1973), além de ser escritor de histórias fantásticas, escreveu o ensaio "Sobre contos de fadas", publicado mais recentemente na obra Árvore e folha. Nesse ensaio, Tolkien responde o que são contos de fadas, sua origem, seus efeitos e sua utilidade. 


\section{SABERES PEDAGÓGICOS}

Revista do Curso de Graduaçāo de Pedagogia - Unesc

ISSN $2526-4559$

Enquanto filólogo, o autor investigou a origem das palavras para estabelecer sua definição de contos de fadas. Para ele, um conto de fadas não é uma história que fala sobre fadas (fairy), aquela espécie particular entre os seres fantásticos, mas um conto sobre o reino encantado (faerie). Assim, um conto de fadas pode abranger não somente fadas como também elfos, anões, bruxas, dragões, gigantes, entre outros. Desse modo, Tolkien define um conto de fadas como “[...] aquele que toca ou usa o Reino Encantado, qualquer que seja seu propósito principal, sátira, aventura, moralidade, fantasia" (TOLKIEN, 2017, p. 10). Desse modo, o autor não coloca todos os contos de fadas em um único modelo, admitindo que há muitas variações e particularidades entre eles.

Uma característica fundamental e comum a todos os contos de fadas é que ele seja apresentado como verdadeiro, ou seja, que aquilo que se passa na história seja real para os personagens e que, de certo modo, também para aquele que o lê. Essa capacidade de crença literária é conhecida como "suspensão voluntária da incredulidade", o que para Tolkien pode ser explicado como o sucesso de um subcriador.

Subcriação é a arte do ser humano de criar, um reflexo da arte do Criador Primário. Ou seja, o subcriador é capaz de criar um mundo secundário que se difere do mundo primário no qual vivemos. Por isso, um bom subcriador é aquele que faz um mundo secundário em que relata a verdade segundo as leis daquele mundo e no qual a mente humana pode entrar e acreditar. Esse estado de acreditar é o da "crença secundária", genuína e autêntica, com "consistência interna da realidade", que não requer a suspensão da incredulidade, uma vez que é o autor que dirige o leitor a crença ao seu mundo subcriado (TOLKIEN, 2017).

Os contos de fadas, como um todo, têm três faces: "a Mística, voltada para o sobrenatural; a Mágica, voltada para a natureza; e o Espelho de desdém e compaixão, voltado para o Homem” (TOLKIEN, 2017, p. 25). Todavia, destaca-se a da Mágica como mais essencial às histórias de fadas.

Os contos de fadas também possuem quatro funções e, portanto, oferecem quatro elementos, são eles: fantasia, recuperação, escape e consolo. Uma qualidade essencial aos contos de fadas é o que Tolkien chama de fantasia, a arte subcriativa que provém da 


\section{SABERES PEDAGÓGICOS}

Revista do Curso de Graduaçāo de Pedagogia - Unesc

ISSN 2526-4559

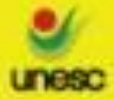

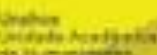

imaginação e que causa estranheza e maravilhamento, já que a fantasia proporciona imagens que não estão presentes na realidade factual, sendo dessemelhantes do Mundo Primário.

A recuperação consiste em retomar uma visão clara das coisas, como disse Tolkien: “não digo 'ver as coisas como elas são', pois assim me envolveria com os filósofos, mas posso arriscar-me a dizer 'ver as coisas como devemos (ou deveríamos) vê-las' - como coisas separadas se nós" (TOLKIEN, 2017, p. 56). Consiste em clarificar nossa visão, retirando a opaca trivialidade e excessiva familiaridade que tornam as coisas sem o brilho que possuíam quando as víamos pela primeira vez. Os contos de fadas podem oferecer essa recuperação com seu poder subcriador, possibilitando a libertação das coisas trancadas como pássaros em gaiola, de modo a percebermos de um novo ângulo aquelas coisas que se tornaram triviais.

Em sua obra, Tolkien estabelece uma distinção entre escape e escapismo, afirmando que os contos de fadas oferecem o escape no sentido de ultrapassar o ordinário e cotidiano. Nesse sentido, quando um leitor adentra no mundo secundário de uma história de fantasia, há satisfação e consolo. De modo particular, nos contos de fadas, esse consolo se apresenta como o Consolo do Final Feliz, chamado também de Eucatástrofe, que pode ser traduzido como a mudança positiva e repentina de alguma situação no final da história.

A visão de J.R.R. Tolkien sobre os contos de fadas, a qual condiz em muitos aspectos com a de Chesterton, revela que esses frutos da subcriação oferecem a oportunidade para vermos as coisas como deveríamos vê-las. Como esses contos trazem o que não é recorrente, mas o que é mágico e fantástico, podemos enxergar às coisas que estão ao nosso redor de modo mais claro, ou seja, o que se tornou trivial se torna lúcido. Por isso, as histórias de fadas oportunizam ultrapassar uma visão determinista e mecânica da realidade, para vê-la em sua contingência. Por operar no nível poético é que é essas histórias tem sua importância no processo educativo.

\subsection{C.S. Lewis e a fantasia literária}

Clive Staples Lewis (1898-1963), que também escreveu histórias fantásticas, como As crônicas de Nárnia, quando era um ateu convicto perguntava-se como homens tão Saberes Pedagógicos, Criciúma, v. 4, n², maio/agosto 2020.- Curso de Pedagogia- UNESC 
inteligentes como São Tomás de Aquino, George MacDonald, Dante Alighieri e G.K. Chesterton podiam acreditar no "conto de fadas religioso", referindo-se ao cristianismo. No entanto, em uma conversa com J.R.R. Tolkien, Lewis acabou reconhecendo a natureza dos mitos e dos contos de fadas, não como mentiras, mas verdades parciais. Dessa conversa, ele saiu um teísta e foi o início de sua conversão ao cristianismo.

A conversão de Lewis está intimamente relacionada com a sua defesa dos contos de fadas, uma vez que compreendendo o "grande mito", tornou-se evidente a realidade de todos os mitos. Em conformidade com a visão de Tolkien e Chesterton, ele defende que o país das fadas não é prejudicial, referindo-se sobretudo às crianças, quando diz:

\begin{abstract}
$\mathrm{O}$ conto de fadas é acusado de dar às crianças uma falsa impressão do mundo em que vivem. Na minha opinião, porém, nenhum outro tipo de literatura que as crianças poderiam ler lhes daria uma impressão tão verdadeira. As histórias infantis que se pretendem "realistas" tendem muito mais a enganar as crianças. Quanto a mim, nunca achei que o mundo real pudesse ser igual aos contos de fadas. Acho que eu esperava que escola fosse igual às histórias da escola. As fantasias não me enganavam, as histórias de escola, sim. (2009, p. 746)
\end{abstract}

Em contraposição aos defensores do "realismo" das histórias, Lewis afirma que os leitores de contos de fadas não confundem a arte com a vida. Enquanto leem uma história, podem se colocar no lugar do personagem, mas sem aceitar ou rejeitar seu ponto de vista. Podem suspender, quando necessário, sua descrença e sua crença, mas não são enganadas quanto ao que é real (LEWIS, 2019).

A fantasia literária, definida por Lewis como "qualquer narrativa que lida como o impossível e o sobrenatural" (2019, p. 60), que é uma atividade realizada de maneira moderada, se difere de uma fantasia egoísta, em que aquele que imagina quer desfrutar de prazeres, honras e triunfos. Estes últimos, definidos como os "não-literatos", não conseguem desfrutar dos contos de fadas por exemplo, pois não enxergam nenhum benefício em ler sobre coisas que nunca aconteceram de verdade. Embora eles não confundam as histórias dos livros que gostam com a realidade, eles querem sentir que poderia acontecer aquilo que leem. $\mathrm{O}$ leitor sabe que o seu sonho, projetado de alguma forma na história que lê, não aconteceu. No entanto, exige que pelo menos seja realizável. E por essa razão, quando se depara com os 


\section{SABERES PEDAGÓGICOS}

Revista do Curso de Graduaçāo de Pedagogia - Unesc

ISSN 2526-4559

contos de fadas e a fantasia, vê que não há a menor possibilidade de as coisas descritas acontecerem com ele no mundo real, e vê essas histórias como sem sentido.

Esses leitores querem ser enganados pelo menos por alguns instantes e precisam de uma plausibilidade das histórias com a realidade, desse modo, "quanto mais a leitura de alguém é uma forma de construção egoísta de castelos, mais exigirá certo realismo superficial e menos gostará do fantástico" (LEWIS, 2019, p. 67). Esse realismo é apenas de conteúdo, pois trata-se de algo provável à vida, diferentemente da fantasia, dos contos de fadas, que não estão preocupados em mostrar o que aconteceu ou poderia acontecer na realidade, mas que propõe o leitor imaginar as consequências de algum acontecimento fantástico.

Isso não significa que, por alegoria ou de algum modo simbólico, os contos de fadas não apontem para aquilo que acontece, uma vez que a função da arte poética é evidenciar aquilo que acontece sempre. No entanto, os contos de fadas satisfazem um anseio diferente em seus leitores em relação àquelas histórias realistas, que satisfazem imaginariamente seus leitores ao proporcionar a fuga de decepções do mundo real. O anseio pelo país das fadas é diferente, pois, como questiona Lewis: "será que alguém supõe que ele, de fato e prosaicamente, anseia pelos perigos e desconfortos de um conto de fadas? - que seu desejo é de fato que houvesse dragões na Inglaterra contemporânea?” (2009, p. 747). A leitura desses contos desperta o anseio por algo que o leitor não identifica muito bem; comove-o e perturba-o, e acrescenta uma nova dimensão de profundidade ao mundo exterior. "O menino não despreza as florestas de verdade por ter lido sobre florestas encantadas: a leitura torna todas as florestas de verdade um pouco encantadas" (LEWIS, 2009, p. 747). Ou seja, os contos de fadas, como já afirmavam Tolkien e Chesterton, trazem recuperação e maravilhamento, proporcionando uma visão clara do mundo em sua essência.

\section{CONCLUSÃO}

A partir do problema levantado e do que foi exposto nesta presente pesquisa bibliográfica, conclui-se que a imaginação é uma faculdade da mente humana indispensável para o processo de aprendizagem, sendo ela mesma a mediadora entre a experiência e a razão. Estando na base de todo o conhecimento, colabora com esse processo na medida que vai Saberes Pedagógicos, Criciúma, v. 4, n², maio/agosto 2020.- Curso de Pedagogia- UNESC 


\section{SABERES PEDAGÓGICOS}

Revista do Curso de Graduaçūo de Pedagogia - Unesc

ISSN 2526-4559

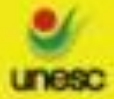

twations

formando o imaginário com um repertório de imagens, as quais influenciam o processo cognitivo de conhecimento e aprendizagem. A literatura, capaz de enriquecer a imaginação e proporcionar um contato com a experiência humana, naquilo que Aristóteles chamou de evento humano típico ou universal, proporciona enriquecedora experiência imaginativa. Capaz de inserir o indivíduo no patrimônio histórico, cultural e moral da humanidade, situa-se como parte integrante da educação.

Os contos de fadas, parte da literatura que compõe as narrativas fantásticas que sempre existiram na humanidade, são histórias capazes de impactar profundamente sobre o imaginário e desenvolver a imaginação. Essas histórias, convictamente defendidas por G.K. Chesterton, J.R.R. Tolkien e C.S. Lewis, potencializam a faculdade imaginativa que forma a base de todo conhecimento. O motivo de essas histórias de fadas possuírem um papel de relevância e destaque no vasto ramo da literatura foi exposto ao apresentar o pensamento desses autores, que manifestaram ser esses contos fantásticos um modo de ver as coisas como realmente são, isto é, afinal, um modo de conhecer.

Desse modo, como foi possível compreender a partir da perspectiva aristotélica, o discurso poético está na base do conhecimento, já que trabalha com a imaginação, e por consequência, com possibilidades. É por meio dessa faculdade que o ser humano é capaz de chegar ao nível da lógica e da demonstração racional. Por essa razão é que, sem uma imaginação bem desenvolvida, o processo educativo torna-se difícil ou até mesmo impossível.

Uma vez que a imaginação possibilita o pensar, uma educação que tem como propósito e fim último a liberdade, somente alcançara seu objetivo perpassando esse caminho, ou seja, seguindo a via do aprender imaginativo. A literatura é a base de toda a educação porque o conhecimento imaginativo é a base de todo o conhecimento. Portanto, a educação que tem como parte integrante a literatura, de modo especial os contos de fadas, propicia uma autêntica formação do ser humano nos princípios da educação liberal, isto é, dotando-o com as armas do conhecimento que o faz verdadeiramente livre. Destarte, a atividade imaginativa é o princípio de toda educação, em que o aprender imaginativo é a via para o aprimoramento da inteligência e para a formação do homem na plenitude de suas dimensões. 


\section{SABERES PEDAGÓGICOS}

Revista do Curso de Graduaçūo de Pedagogia - Unesc

ISSN 2526-4559

\section{REFERÊNCIAS}

AQUINO, Tomas de. Suma Teológica. v. 1. São Paulo: Loyola. 2ed. 2003. 704 p.

ARISTÓTELES; HORÁCIO; LONGINO. A poética clássica. 12. ed. São Paulo: Cultrix, 2005. $114 \mathrm{p}$.

ARISTÓTELES. Sobre a alma. Lisboa: Imprensa Nacional Casa da moeda, 2010. 152 p.

ARITÓTELES. Metafísica. 2. ed. São Paulo: Edipro, 2012. 368 p.

CHESTERTON, Gilbert Keith. Educação por meio dos contos de fadas. 1905. Disponível em: <https://www.sociedadechestertonbrasil.org/educacao-por-meio-dos-contos-de-fadas/>. Acesso em: 16 out. 19.

CHESTERTON, G.K. Ortodoxia. São Paulo: Ecclesiae, 2013 a. 279 p.

CHESTERTON, G.K. Contos de fadas e outros ensaios literários. São Luís, MA:

Resistência Cultural, 2013 b. 356 p.

COELHO, Nelly Novaes. O conto de fadas. São Paulo: Ática, 1987. 92 p.

DURIEZ, Colin. O dom da amizade: Tolkien e C.S. Lewis. 1. ed. Rio de Janeiro: Nova Fronteira, 2006. 310 p.

FAITANIN, Paulo. O papel dos sentidos internos na teoria do conhecimento de Tomás de Aquino. AQUINATE, jan/jun. 2008. v. 4, n. 6. p. 234-241. Disponível em: < http://www.aquinate.com.br/textos/o-papel-dos-sentidos-internos-na-teoria-do-conhecimentode-tomas-de-aquino/>. Acesso em 20 set. 2019.

FRYE, Northrop. A imaginação educada. Campinas, SP: Vide Editorial, 2017. 134 p.

JAEGER, Werner Wilhelm. Paidéia a formação do homem grego. 2 ed. São Paulo: M. Fontes, 1989. 966 p.

JOLIVET, Régis. Curso de filosofia. 2. ed. Rio de Janeiro: Agir, 1955. 467 p.

JOSEPH, Irmã Miriam. Trivium: as artes liberais da lógica, da gramática e da retórica. São Paulo: É Realizações, 2008. 327 p.

LAND, Andrew. O fabuloso livro azul. Porto Alegre, RS: Concreta, 2016. 472 p.

LEWIS. C.S. Um experimento em crítica literária. Rio de Janeiro: Thomas Nelson, 2019. $160 \mathrm{p}$.

Saberes Pedagógicos, Criciúma, v. 4, n², maio/agosto 2020.- Curso de Pedagogia- UNESC 
LEWIS, C.S. As crônicas de Nárnia - Volume Único. São Paulo: Martins Fontes, 2009.

MACDONALD, George. The Imagination: Its Function and its Culture. 1867. Disponível em: < http://www.george-macdonald.com/etexts/the imagination.html>. Acesso em 24 abril 2019.

MACDONALD, George. The fantastic imagination. A Dish of Orts: Papers on Imagination. 1893. London: Library of Alexandria, 2013.

MARITAIN, Jacques. Rumos da educação. 5. ed. Rio de Janeiro: Agir, 1968. 306 p.

PRADO, Lourenço de Almeida. Educação: ajudar a pensar, sim, conscientizar, não. Rio de Janeiro: Agir, 1991. 391 p.

SANTOS, Maria de Fátima Ribeiro dos; SANTOS, Saulo Ribeiro dos. Metodologia da pesquisa em educação. São Luís: UemaNet, 2010. 67 p.

TOLKIEN, J.R.R. Árvore e folha. 2. ed. São Paulo: Martins Fontes, 2017. 106 p.

ZAMBONI, Fausto José da Fonseca. Literatura, ensino e educação liberal. 2011. 186 f. Tese (Doutorado em Letras). - Faculdade de Ciências e Letras, Universidade Estadual Paulista, Assis, 2011.

ZAMBONI, Fausto. Contra a escola: ensaio sobre literatura, ensino e Educação Liberal. Campinas, SP: Vide Editorial, 2016. 294 p. 